\title{
SOD3 and eNOS genotypes are associated with SOD activity and $\mathrm{NO}_{\mathrm{x}}$
}

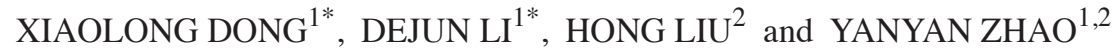 \\ ${ }^{1}$ Department of Clinical Genetics, Shengjing Hospital of China Medical University, Shenyang, Liaoning 110004; \\ ${ }^{2}$ Department of Medical Genetics, China Medical University, Shenyang, Liaoning 110001, P.R. China
}

Received December 18, 2013; Accepted May 2, 2014

DOI: $10.3892 /$ etm.2014.1720

\begin{abstract}
Oxidative stress, characterized by increased reactive oxygen species production and/or decreased antioxidant enzyme activity, plays an important role in the pathogenesis of hypertension. The identification of molecular markers corresponding to the oxidative stress status of hypertension may assist in the antioxidant therapy of hypertension. In the present study, superoxide dismutase (SOD) and endothelial nitric oxide synthase (eNOS) were analyzed as markers of hypertension responding to oxidative stress. The plasma SOD activity and mononitrogen oxides $\left(\mathrm{NO}_{\mathrm{x}}\right)$ concentration were measured, and the SOD3 Ala58Thr and eNOS Glu298Asp polymorphisms were genotyped in hypertensive patients and normotensive controls. Further association experiments were replicated in an extended population, including 343 hypertensive patients and 290 controls. The results demonstrated that no statistically significant differences in the total SOD activity and $\mathrm{NO}_{\mathrm{x}}$ concentration were identified between the hypertensive patients and controls. However, the plasma SOD activity levels in the SOD3 Ala/Ala homozygote carriers $(80.51 \pm 27.68 \mathrm{U} / \mathrm{ml})$ were significantly lower compared with the Thr allele carriers $(92.18 \pm 16.37 \mathrm{U} / \mathrm{ml} ; \mathrm{P}=0.031)$. In addition, the plasma $\mathrm{NO}_{\mathrm{x}}$ concentration in the eNOS Glu/Glu homozygote carriers $(129.66 \pm 59.15 \mu \mathrm{mol} / \mathrm{l})$ was significantly lower compared with the Asp allele carriers (169.84 $55.18 \mu \mathrm{mol} / \mathrm{l}$; $\mathrm{P}=0.010)$. Notably, the altered SOD activity levels and $\mathrm{NO}_{x}$ concentration were in concordance in $56.3 \%$ of the 80 participants. Therefore, the concordance of decreased SOD activity and $\mathrm{NO}_{\mathrm{x}}$ concentration, combined with genotypes of SOD3 Ala/Ala and/or eNOS Glu/Glu in hypertensive patients, may be useful in directing the antioxidant therapy of hypertension.
\end{abstract}

Correspondence to: Professor Yanyan Zhao, Department of Clinical Genetics, Shengjing Hospital of China Medical University, 36 San Hao Street, Shenyang, Liaoning 110004, P.R. China

E-mail: yyzhao@sj-hospital.org; yyzhao@mail.cmu.edu.cn

*Contributed equally

Key words: nitric oxide synthase, oxidative stress, polymorphism, superoxide dismutase, hypertension

\section{Introduction}

Hypertension is a major contributor to the development of cardiovascular, cerebrovascular and renal disease, and is influenced by genetic and environmental determinants. A large body of evidence indicates that endothelial dysfunction resulting from oxidative stress is a functional and reversible alteration of endothelial cells, which is characteristic of patients with hypertension (1-4).

Oxidative stress refers to an imbalanced redox status where pro-oxidants overwhelm the antioxidant capacity, resulting in the excessive generation of reactive oxygen species (ROS). Under physiological conditions, ROS function as important intracellular and intercellular secondary messengers to maintain the vascular function and integrity. However, under pathophysiological conditions, increased levels of ROS contribute to endothelial dysfunction and vascular remodeling. The superoxide anion $\left(\mathrm{O}_{2}^{-}\right)$is the major ROS produced by endothelial and vascular smooth muscle cells, against which superoxide dismutase (SOD), as the first antioxidant defense system, protects to maintain the redox homeostasis. Three isoforms of SOD exist in mammalian cells, including cytoplasmic $\mathrm{Cu} / \mathrm{Zn}$ SOD (SOD1), mitochondrial Mn SOD (SOD2) and extracellular SOD (SOD3). Among them, SOD3 is the major plasma SOD released from the tissue interstitium, which participates in scavenging $\mathrm{O}_{2}^{-}(5)$. In addition, $\mathrm{O}_{2}^{-}$can react with nitric oxide (NO) to form peroxynitrite $\left(\mathrm{ONOO}^{-}\right)$ that further oxidizes tetrahydrobiopterin $\left(\mathrm{BH}_{4}\right)$, a cofactor of nitric oxide synthase (NOS), which leads to NOS uncoupling, producing $\mathrm{O}_{2}{ }^{-}$and reducing the bioavailability of $\mathrm{NO}$ in the arteries $(6,7)$. This dynamic alteration of ROS plays an important role in the pathogenesis of hypertension.

Based on the occurrence of oxidative stress in hypertension, the modification of antioxidant activity and NO bioavailability is considered an accessorial therapy for hypertension. Several antioxidant trials have been conducted with the aim of preventing or treating hypertension, including supplements of vitamin E, vitamin $\mathrm{C}$ or combinations. Although a few studies with a small sample size have demonstrated the beneficial effect of antioxidants in controlling hypertension, other larger trials have failed to confirm the effect of antioxidants on the development of hypertension or the control of blood pressure (8-12). These clinical trials have raised questions with regard to the oxidative stress status of hypertensive individuals 
as compared with normotensive controls. Furthermore, the correlation between plasma SOD activity and NO concentration has rarely been considered when interpreting the effect of antioxidant therapy in hypertension.

Thus, the aim of the present study was to evaluate SOD activity and NO concentration in hypertensive individuals and normotensive controls recruited from a rural area in Northeast China. The patients had not received any therapy. This relatively homogeneous population was useful for determining the redox status. In addition, associations between SOD activity and the Ala58Thr polymorphism (c.172G $>$ A, rs2536512) in the SOD3 gene and mononitrogen oxides $\left(\mathrm{NO}_{\mathrm{x}}\right)$ concentration with the Glu298Asp polymorphism (c.894G>T, rs1799983) in the endothelial nitric oxide synthase (eNOS) gene were investigated.

\section{Methods}

Subjects. In total, 633 subjects of Han Chinese origin, including 343 unrelated hypertensive patients and 290 unrelated normotensive controls, were recruited from a relatively isolated rural area in Northeast China. Blood pressure (BP) was measured three times from the right arm of seated subjects after at least 5 min of rest. Hypertension was defined as an average systolic $\mathrm{BP}$ of $\geq 140 \mathrm{mmHg}$ or an average diastolic $\mathrm{BP}$ of $\geq 90 \mathrm{mmHg}$. Patients were excluded from the study if they suffered from diabetes mellitus, renal disease or secondary hypertension, as determined by history inquiry and physical examination. All the individuals underwent routine laboratory tests that determined the levels of serum triglyceride (TG), total cholesterol (T-chol), high-density lipoprotein cholesterol (HDL-chol), low-density lipoprotein cholesterol (LDL-chol) and glucose. Informed consent was obtained from all the participants and ethical approval was provided by the local Ethics Committee (Shengjing Hospital of China Medical University, Shenyang, China).

Measurement of plasma SOD activity and $\mathrm{NO}_{x}$ concentration Plasma SOD activity and $\mathrm{NO}_{x}$ concentration were measured in 54 hypertensive patients and 26 normotensive controls, who were selected from the 633 subjects since they had not received antihypertensive therapy or other drugs. Measurements were performed using commercially available kits (No. A001-2/ A013-1, Nanjing Jiancheng Bioengineering Institute, Nanjing, China), according to the manufacturer's instructions. SOD activity was detected using chemical colorimetry, while the $\mathrm{NO}_{x}$ concentration was determined using nitrate reductase to convert nitrate $\left(\mathrm{NO}_{3}^{-}\right)$to nitrite $\left(\mathrm{NO}_{2}^{-}\right)$, which was then detected by colorimetry.

Genotyping. High-molecular weight genomic DNA was extracted from plasma buffy coats using a Flexigene kit (No. 51104, Qiagen GmbH, Hilden, Germany), according to the manufacturer's instructions. Genotypes were determined using an Assays-on-Demand kit(No.C_2668728_10/C_3219460_20, Thermo Fisher Scientific, Foster City, CA, USA) in addition to TaqMan polymerase chain reaction (PCR) assays (No.4352042, Thermo Fisher Scientific). The probes and primers used in the TaqMan ${ }^{\circledR}$ single nucleotide polymorphism (SNP) genotyping assays (C_2668728_10 for SOD3 Ala58Thr; C_3219460_20
Table I. Concordance of SOD activity and $\mathrm{NO}_{\mathrm{x}}$ concentration in HTN patients and controls.

Concordance

\begin{tabular}{lccc}
\cline { 2 - 4 } SOD or $\mathrm{NO}_{\mathrm{x}}$ & Total, n (\%) & HTN, n (\%) & Control, n (\%) \\
\hline Above average & $23(28.8)$ & $13(16.3)$ & $10(12.5)$ \\
Below average & $22(27.5)$ & $17(21.2)$ & $5(6.3)$ \\
\hline
\end{tabular}

HTN, hypertensive; SOD, superoxide dismutase; $\mathrm{NO}_{\mathrm{x}}$, mononitrogen oxides.

for eNOS Glu298Asp) were purchased from Thermo Fisher Scientific. PCR was performed in a total volume of $25 \mu \mathrm{l}$ per single well reaction in a 96 -well plate containing $20 \mathrm{ng}$ genomic DNA, $0.625 \mu 1$ TaqMan ${ }^{\circledR}$ SNP Genotyping Assay Mix (40X) and $12.5 \mu \mathrm{l} \mathrm{TaqMan}{ }^{\circledR}$ Universal PCR Master Mix (2X). The thermal cycling conditions were $95^{\circ} \mathrm{C}$ for $10 \mathrm{~min}$, followed by 40 cycles of DNA denaturation at $92^{\circ} \mathrm{C}$ for $15 \mathrm{sec}$ and annealing/ extension at $60^{\circ} \mathrm{C}$ for $1 \mathrm{~min}$. PCR was performed using the ABI 7500 Real-Time system (Thermo Fisher Scientific). DNA samples of known genotype and DNase-free water were used as positive controls and nontemplate controls in each assay run. Signals were processed and analyzed using the Sequence Detection System version 1.4 software package (Thermo Fisher Scientific). The samples genotyped Ala/Ala, Ala/Thr and Thr/Thr for SOD3 Ala58Thr, and Glu/Glu, Glu/Asp and Asp/Asp for eNOS Glu298Asp were selected randomly and confirmed by sequencing (3730 Genetic Analyzer; Thermo Fisher Scientific).

Statistical analysis. Statistical analysis was performed with SPSS version 13.0 for Windows (SPSS, Inc., Chicago, IL, USA). Hardy-Weinberg equilibrium was assessed using the $\chi^{2}$ test. Clinical characteristics are presented as the mean \pm standard deviation. Differences between two groups were assessed using the independent-sample t-test for quantitative variables and the $\chi^{2}$ test for categorical variables. Comparisons among three groups were performed by one-way analysis of variance. Adjusted odds ratios with $95 \%$ confidence intervals from the logistic regression analyses were used to estimate the relative risk for hypertension, while correlation analyses were used to determine the associations between quantitative variables. $\mathrm{P}<0.05$ was considered to indicate a statistically significant difference.

\section{Results}

SOD activity in the hypertensive patients and controls. Total SOD activity in the plasma embodies the antioxidant defense against $\mathrm{O}_{2}{ }^{-}$and is predominantly attributable to SOD3, which exists exclusively in the extracellular space. Plasma SOD activity was assayed in 80 participants, including 54 hypertensive patients and 26 normotensive controls that had not undergone therapy. As shown in Fig. 1A, there was no statistically significant difference in the average levels of total SOD activity between the hypertensive patients and controls, 
A

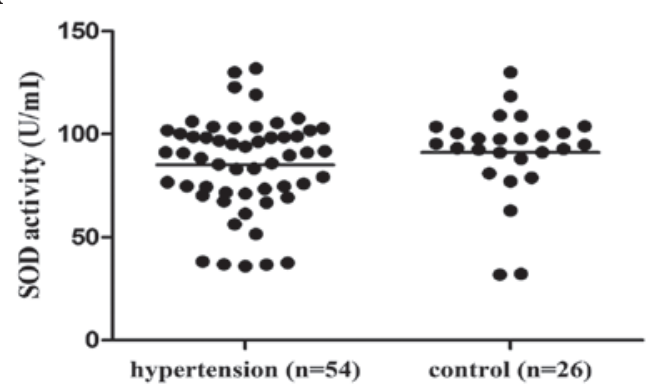

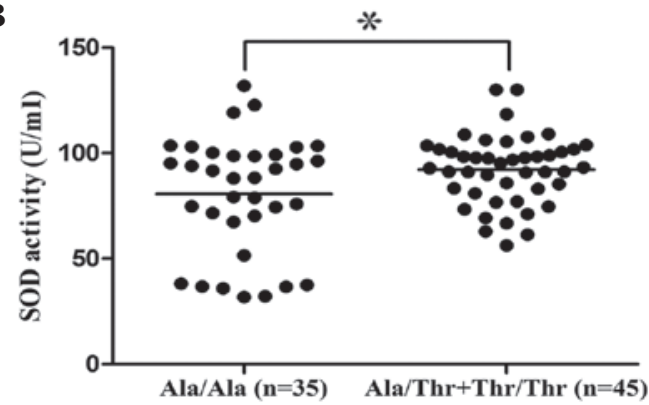

Figure 1. (A) Total plasma SOD activity in hypertensive patients and controls. (B) Association between the SOD3 Ala58Thr genotype and SOD activity. SOD activity levels in the Ala/Ala homozygote carriers were significantly lower than those in the Thr allele carriers ("P=0.031). SOD, superoxide dismutase.

A

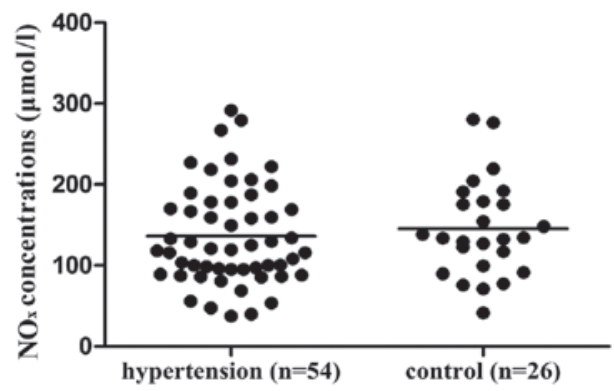

B

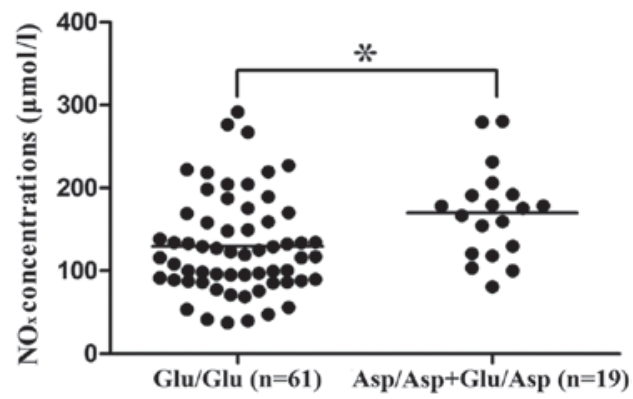

Figure 2. (A) Plasma $\mathrm{NO}_{x}$ concentration in the hypertensive patients and controls. (B) Association between the eNOS Glu298Asp genotype and $\mathrm{NO}_{\mathrm{x}}$ concentration. $\mathrm{NO}_{\mathrm{x}}$ concentrations in the Glu/Glu homozygote carriers were significantly lower than in the Asp allele carriers ( $\left.\mathrm{P}=0.010\right)$. $\mathrm{NO}_{\mathrm{x}}$, mononitrogen oxides; eNOS, endothelial nitric oxide synthase.

however, the interindividual variability was more marked in the hypertensive patients than in the controls, indicating diverse susceptibilities of the antioxidant response to $\mathrm{O}_{2}{ }^{-}$in hypertensive patients.

Association between the SOD3 Ala58Thr polymorphism and SOD activity. The SOD3 Ala58Thr (c.172G $>$ A) polymorphism at amino acid 40 in the amino terminal region of mature SOD3 is considered to be essential for tetramerization. In order to evaluate the association between the Ala58Thr polymorphism and plasma SOD activity, the SOD3 Ala58Thr polymorphism was genotyped using quantitative PCR in the same 80 participants whose plasma SOD activity levels were measured. As shown in Fig. 1B, plasma SOD activity in the SOD3 Ala/Ala homozygote carriers $(80.51 \pm 27.68 \mathrm{U} / \mathrm{ml})$ was significantly lower than in the Thr allele carriers $(92.18 \pm 16.37 \mathrm{U} / \mathrm{ml} ; \mathrm{P}=0.031)$, indicating that the SOD3 Ala58Thr genotype was associated with decreased plasma SOD activity in a recessive model for the Ala allele.

$N O_{x}$ concentration in the hypertensive patients and controls. $\mathrm{NO}$ released from the cells was rapidly oxidized to $\mathrm{NO}_{2}{ }^{-}$and $\mathrm{NO}_{3}^{-}$, termed $\mathrm{NO}_{\mathrm{x}}$. These molecules are relatively stable in blood, thus, the plasma $\mathrm{NO}_{\mathrm{x}}$ concentration may be an indicator of the endogenous formation of NO. The median plasma $\mathrm{NO}_{\mathrm{x}}$ concentration in the hypertensive patients $(136.2 \mu \mathrm{mol} / \mathrm{l}$; interquartile range, 37.6-291.7 $\mu \mathrm{mol} / \mathrm{l}$ ) was not significantly different from the controls $(145.4 \mu \mathrm{mol} / 1$; interquartile range, 41.4-280.6 $\mu \mathrm{mol} / \mathrm{l})$. However, there was a decreased tendency in $\mathrm{NO}_{\mathrm{x}}$ concentration in the hypertensive patients, indicating more frequent occurrence of eNOS uncoupling (Fig. 2A).
Association between the eNOS Glu298Asp polymorphism and $N O_{x}$ concentration. To identify whether the eNOS Glu298Asp (c.894G $>$ T) polymorphism was associated with the plasma $\mathrm{NO}_{\mathrm{x}}$ concentration, the Glu298Asp polymorphism was genotyped in 80 participants whose plasma $\mathrm{NO}_{\mathrm{x}}$ concentration had been detected. As shown in Fig. 2B, the plasma $\mathrm{NO}_{x}$ concentration in the eNOS Glu/Glu homozygote carriers $(129.66 \pm 59.15 \mu \mathrm{mol} / \mathrm{l})$ was significantly lower compared with the Asp allele carriers $(169.84 \pm 55.18 \mu \mathrm{mol} / 1 ; \mathrm{P}=0.010)$, indicating that the eNOS Glu298Asp genotype was associated with decreased plasma $\mathrm{NO}_{\mathrm{x}}$ concentrations in a recessive model for the Glu allele.

Concordance of SOD and $N_{x}$ in hypertensive patients and controls. Concordance of SOD and $\mathrm{NO}_{x}$ refers to the uniform alteration of SOD activity and $\mathrm{NO}_{\mathrm{x}}$ concentration in each individual. As shown in Table I, 56.3\% of the 80 participants were in concordance, among them, 23 subjects had above average values of SOD and $\mathrm{NO}_{\mathrm{x}}$, while 22 subjects had below average values. The individuals with below average values were predominantly hypertensive patients (17/22), of which the SOD3 Ala/Ala and/or eNOS Glu/Glu genotype accounted for $88.2 \%$.

Association study in a case-control population. Considering the associations between SOD3 Ala58Thr and plasma SOD activity and between eNOS Glu298Asp and $\mathrm{NO}_{\mathrm{x}}$ concentration, the association between the polymorphisms and hypertension was investigated in a case-control population, including 343 hypertensive patients and 290 normotensive controls. As shown in Table II, serum TG, T-chol, LDL-chol, 
Table II. Baseline characteristics of the case-control population.

\begin{tabular}{lccr}
\hline Characteristics & HTN $(\mathrm{n}=343)$ & Control (n=290) & P-value \\
\hline Male/female, $\mathrm{n}$ & $146 / 197$ & $116 / 174$ & 0.515 \\
Age, years & $48.23 \pm 9.15$ & $47.46 \pm 8.43$ & 0.277 \\
SBP, $\mathrm{mmHg}$ & $166.78 \pm 20.18$ & $113.29 \pm 9.19$ & $<0.001$ \\
DBP, $\mathrm{mmHg}$ & $104.34 \pm 12.00$ & $74.43 \pm 6.26$ & $<0.001$ \\
TG, $\mathrm{mmol} / \mathrm{l}$ & $1.58 \pm 1.17$ & $1.14 \pm 1.05$ & $<0.001$ \\
T-chol, $\mathrm{mmol} / \mathrm{l}$ & $5.07 \pm 0.97$ & $4.72 \pm 1.01$ & $<0.001$ \\
LDL-chol, mmol/1 & $3.05 \pm 0.76$ & $2.73 \pm 0.79$ & $<0.001$ \\
HDL-chol, mmol/1 & $1.52 \pm 0.37$ & $1.67 \pm 0.50$ & $<0.001$ \\
Glucose, $\mathrm{mmol} / \mathrm{l}$ & $4.83 \pm 1.50$ & $4.63 \pm 1.40$ & 0.097 \\
Potassium, $\mathrm{mmol} / \mathrm{l}$ & $4.15 \pm 0.40$ & $4.23 \pm 0.38$ & 0.011 \\
Sodium, $\mathrm{mmol} / \mathrm{l}$ & $144.32 \pm 3.75$ & $143.61 \pm 4.28$ & 0.026
\end{tabular}

Data are expressed as the mean \pm SD. HTN, hypertensive; SBP, systolic blood pressure; DBP, diastolic blood pressure; TG, triglyceride; T-chol, total cholesterol; LDL-chol, low-density lipoprotein cholesterol; HDL-chol, high-density lipoprotein cholesterol.

Table III. Genotype and allele distributions of SOD3 Ala58Thr and eNOS Glu298Asp in the case-control population.

\begin{tabular}{|c|c|c|c|c|}
\hline Parameter & HTN, n (\%) & Control, n (\%) & OR $(95 \% \mathrm{CI})$ & P-value \\
\hline \multicolumn{5}{|c|}{ SOD3 Ala58Thr } \\
\hline \multicolumn{5}{|l|}{ Genotype } \\
\hline Ala/Ala & $158(46.1)$ & $132(45.5)$ & & \\
\hline Ala/Thr & $154(44.9)$ & $130(44.8)$ & & 0.963 \\
\hline Thr/Thr & $31(9.0)$ & $28(9.7)$ & & \\
\hline $\mathrm{OR}^{\mathrm{a}}$ & & & $0.930(0.544-1.590)$ & 0.790 \\
\hline $\mathrm{OR}^{\mathrm{b}}$ & & & $0.978(0.715-1.339)$ & 0.891 \\
\hline \multicolumn{5}{|l|}{ Allele } \\
\hline Ala & $470(68.5)$ & $394(67.9)$ & & \\
\hline Thr & $216(31.5)$ & $186(32.1)$ & & \\
\hline OR & & & $1.027(0.810-1.302)$ & 0.825 \\
\hline \multicolumn{5}{|c|}{ eNOS Glu298Asp } \\
\hline \multicolumn{5}{|l|}{ Genotype } \\
\hline Glu/Glu & 257 (74.9) & $224(77.2)$ & & \\
\hline Glu/Asp & $81(23.6)$ & $64(22.1)$ & & 0.573 \\
\hline Asp/Asp & $5(1.5)$ & $2(0.7)$ & & \\
\hline $\mathrm{OR}^{\mathrm{a}}$ & & & $2.130(0.410-11.062)$ & 0.357 \\
\hline $\mathrm{OR}^{\mathrm{b}}$ & & & $1.136(0.787-1.640)$ & 0.497 \\
\hline \multicolumn{5}{|l|}{ Allele } \\
\hline Glu & $595(86.7)$ & $512(88.3)$ & & \\
\hline Asp & $91(13.3)$ & 68 (11.7) & & \\
\hline OR & & & $0.868(0.621-1.215)$ & 0.410 \\
\hline
\end{tabular}

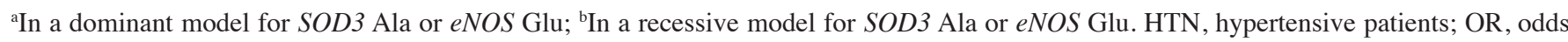
ratio; 95\% CI, 95\% confidence interval; SOD, superoxide dismutase; eNOS, endothelial nitric oxide synthase.

potassium and sodium levels were higher in the hypertensive patients compared with the controls; whereas, HDL-chol was lower in the hypertensive patients compared with the controls. Correlation analysis revealed positive associations between serum TG, T-chol, LDL-chol and glucose with BP; whereas, serum HDL-chol and potassium were shown to be negatively associated with BP.

Genotype distributions of SOD3 Ala58Thr and eNOS Glu298Asp were in Hardy-Weinberg equilibrium. As shown in Table III, neither genotype nor allele frequency was shown 
to be significantly different between the hypertensive patients and normotensive controls.

\section{Discussion}

Oxidative stress is characterized by increased ROS production and/or decreased antioxidant enzyme activity. SOD is the predominant antioxidant enzyme that protects the cell from oxidative damage by converting $\mathrm{O}_{2}^{-}$to hydrogen peroxide. Plasma SOD activity levels have been found to be altered in a number of diseases, including ovarian cancer (13), idiopathic respiratory distress syndrome and colorectal cancer $(14,15)$, and are considered to be a good marker for detecting and monitoring these diseases. However, data on the change of SOD activity in experimental and human hypertension studies are inconsistent. In spontaneously hypertensive rats, SOD3 activity levels was observed to be significantly decreased (16), and overexpression of SOD3 reduced systemic vascular resistance and arterial pressure (17). In humans, plasma SOD activity was reported to be significantly reduced when compared with normotensive controls $(18,19)$. However, certain studies have reported no change or higher plasma SOD activity with hypertension $(20,21)$. In the present study, the plasma SOD activity levels were assessed in hypertensive patients for further use as a diagnostic or healing marker. Plasma SOD activity was measured in 80 subjects that had not received therapy, including 54 hypertensive patients and 26 normotensive controls, from a relatively homogeneous population. No statistically significant difference was observed in the average plasma SOD activity between the hypertensive patients and controls, however, the interindividual variability of SOD activity was more marked in the hypertension patients than in the controls. This variation may have been caused by the SOD3 polymorphisms that have been widely studied $(22,23)$. One functional variant, a Gly213 substitution for Arg213 (Arg213Gly) at the heparin-binding domain of SOD3, results in a 10 -fold increase in plasma SOD3 activity levels and a decrease in tissue SOD3 activity levels (24). High plasma activity can be explained by an accelerated release from the tissue interstitium. However, the Gly213 carriers account for 4\% of Swedish, 3\% of Australian and $6 \%$ of Japanese populations that have been studied (25-27), and SOD activity variation cannot be ascribed to the relatively rare variant. The SOD3 Ala58Thr polymorphism is located at amino acid 40 in the amino terminal region of mature SOD3 and is considered to be essential for tetramerization. However, little is known with regard to the effect of Ala58Thr on SOD activity. Thus, the SOD3 Ala58Thr polymorphism was further genotyped to identify whether there was an association between the genotype and plasma SOD activity. The Ala/Ala homozygote carriers were found to have decreased SOD activity levels when compared with the Thr allele carriers. However, no difference between this polymorphism and SOD activity was found in a Japanese population (28). This difference may be caused by the different study populations.

SOD3 is potentially involved in the mechanism responsible for the impairment of plasma NO bioavailability. In endothelial cells, NO is predominantly produced from L-arginine by eNOS. Under normal conditions, the active form of eNOS is a homodimer and exhibits an antihypertensive effect via the function of NO, which inhibits platelet adhesion to the endo- thelium and relaxes the vascular smooth muscle. However, in the absence of the substrate L-arginine or $\mathrm{BH}_{4}$, eNOS exists in an inactive monomer form and produces $\mathrm{O}_{2}^{-}$rather than NO. Furthermore, $\mathrm{O}_{2}^{-}$can react with $\mathrm{NO}$ to form a potent oxidizing agent, peroxynitrite $\left(\mathrm{ONOO}^{-}\right)$, leading to the reduction of $\mathrm{NO}$ bioavailability and endothelial dysfunction. Therefore, eNOS may exhibit an anti- or a prohypertensive effect (29). In the present study, no statistically significant difference in $\mathrm{NO}_{\mathrm{x}}$ concentration was observed between the hypertensive patients and controls, however, there was a decreased tendency in $\mathrm{NO}_{\mathrm{x}}$ concentration in the hypertensive patients. The results were in accordance with the study by Node et al (30) that reported that the plasma NO concentration was reduced in patients with hypertension. However, Sandrim et al (31) found that $\mathrm{NO}_{\mathrm{x}}$ concentrations were increased in hypertensive patients, indicating that the increased NO level may play a compensatory role. With regard to eNOS polymorphisms, three have been widely studied: $786 \mathrm{~T} / \mathrm{C}$ in the promoter region, a 27-bp variable number of tandem repeats in intron 4 (intron4b/a) and Glu298Asp (c.894G $>$ T) in exon 7. The Glu298Asp polymorphism is located between the critical residue of the heme domain and the binding sites for L-arginine and $\mathrm{BH}_{4}(32)$. Therefore, the substitution of Glu by Asp may result in an alteration of eNOS activity and plasma NO production. Association studies between eNOS Glu298Asp and plasma $\mathrm{NO}_{\mathrm{x}}$ concentration have produced inconsistent results (33-37). In the present study, the Glu/Glu homozygote carriers had significantly lower $\mathrm{NO}_{\mathrm{x}}$ concentrations than the Asp allele carriers, which was in accordance with the study by Yoon et al (36). However, an association between the polymorphism and eNOS expression or eNOS enzyme activity was not observed in cultured umbilical vein endothelial cells in their subsequent study (37). Metzger et al demonstrated no variation in $\mathrm{NO}_{\mathrm{x}}$ concentration across the genotypes (38). Therefore, the effect that the eNOS Glu298Asp polymorphism has on plasma $\mathrm{NO}_{\mathrm{x}}$ concentration in the population of the present study may require further identification using larger test samples.

SOD regulates the bioavailability of NO via the reduction of $\mathrm{O}_{2}^{-}$, which reacts with NO. Due to the interaction of SOD and NO in the plasma, their concordance was calculated to evaluate the individual redox status. Of the 80 tested subjects, $56.3 \%$ exhibited good concordance and the sum of the individuals with above average values of SOD activity and $\mathrm{NO}_{\mathrm{x}}$ concentration $(n=23)$ was close to those with below average values $(n=22)$. Individuals with $\mathrm{SOD}$ and $\mathrm{NO}_{\mathrm{x}}$ below average values were primarily hypertensive patients carrying the SOD3 Ala/Ala and/or eNOS Glu/Glu genotypes, which coincided with the association of phenotype with SOD3 and eNOS genotypes. Therefore, the concordance of plasma SOD activity and $\mathrm{NO}_{\mathrm{x}}$ concentration combined with their genotypes was hypothesized to be valuable to antioxidant trials of hypertension. In addition, an extended case-control population was genotyped, including 343 hypertensive patients and 290 unrelated controls from the same region in Northeast China. However, an association between SOD3 Ala58Thr and hypertension was not identified. Thus far, studies on the association between human SOD3 Ala58Thr and hypertension have produced inconsistent results, with significant positive associations in specific studies (39-41), but not in others (42). This inconsistency may derive from population stratification of ethnicity. In the present 
case-control population, Ala was the major allele of SOD3 Ala58Thr (68.5\%), which is the same as Spanish (63\%) (41) and Japanese (71.0\%) (42) populations, but Thr is the major allele in a Romanian $(67.0 \%)$ population (40). With regard to the eNOS Glu298Asp polymorphism, the association with hypertension is also controversial. Miyamoto et al reported that the Asp allele was associated with hypertension in a Japanese population (43) and Lacolley et al found that the Glu allele was associated with hypertension in Caucasians (44). However, other studies have not replicated the association between eNOS Glu298Asp and hypertension in Japanese, Caucasian and African American populations (45-47). In the present study, an association between eNOS Glu298Asp and hypertension was not observed in the case-control population, confirming the results of a previous study that reported that the polymorphism was unlikely to be a major genetic susceptibility factor for hypertension in the north Han Chinese population (48).

In conclusion, the present study demonstrated an association between the SOD3 Ala58Thr polymorphism and plasma SOD activity, as well as an association between the eNOS Glu298Asp polymorphism and plasma $\mathrm{NO}_{\mathrm{x}}$ concentrations in a Northeastern Chinese population. Ala/Ala homozygote carriers at the SOD3 Ala58Thr locus had decreased plasma SOD activity levels, while the Glu/Glu homozygote carriers at the eNOS Glu298Asp locus had decreased plasma $\mathrm{NO}_{\mathrm{x}}$ concentrations. The concordance between decreased SOD activity and $\mathrm{NO}_{\mathrm{x}}$ concentration, combined with the genotypes of SOD3 Ala/Ala and/or eNOS Glu/Glu in hypertensive patients, may be useful in directing the antioxidant therapy of hypertension.

\section{Acknowledgements}

The study was supported by grants from the Special Fund of Prior Period for Key Project of Chinese National Programs for Fundamental Research and Development (973 program) (no. 2009CB526401) and the National Natural Science Foundation of China (nos.81070206 and 30800463).

\section{References}

1. Panza JA, Quyyumi AA, Brush JE Jr and Epstein SE: Abnormal endothelium-dependent vascular relaxation in patients with essential hypertension. N Engl J Med 323: 22-27, 1990.

2. Panza JA, Casino PR, Kilcoyne CM and Quyyumi AA: Role of endothelium-derived nitric oxide in the abnormal endothelium-dependent vascular relaxation of patients with essentia hypertension. Circulation 87: 1468-1474, 1993.

3. Perticone F, Ceravolo R, Pujia A and et al: Prognostic significance of endothelial dysfunction in hypertensive patients Circulation 104: 191-196, 2001.

4. Le Brocq M, Leslie SJ, Milliken P and Megson IL: Endothelial dysfunction: from molecular mechanisms to measurement, clinical implications, and therapeutic opportunities. Antioxid Redox Signal 10: 1631-1674, 2008.

5. Strålin P, Karlsson K, Johansson BO and Marklund SL: The interstitium of the human arterial wall contains very large amounts of extracellular superoxide dismutase. Arterioscler Thromb Vasc Biol 15: 2032-2036, 1995

6. Kuzkaya N, Weissmann N, Harrison DG and Dikalov S: Interactions of peroxynitrite, tetrahydrobiopterin, ascorbic acid and thiols: implications for uncoupling endothelial nitric-oxide synthase. J Biol Chem 278: 22546-22554, 2003.

7. Laursen JB, Somers M, Kurz S, et al: Endothelial regulation of vasomotion in apoE-deficient mice: implications for interactions between peroxynitrite and tetrahydrobiopterin. Circulation 103: 1282-1288, 2001.
8. Houston MC: The role of cellular micronutrient analysis, nutraceuticals, vitamins, antioxidants and minerals in the prevention and treatment of hypertension and cardiovascular disease. Ther Adv Cardiovasc Dis 4: 165-183, 2010.

9. Sherman DL, Keaney JF Jr, Biegelsen ES, et al: Pharmacological concentrations of ascorbic acid are required for the beneficial effect on endothelial vasomotor function in hypertension. Hypertension 35: 936-941, 2000.

10. Engelhard YN, Gazer B and Paran E: Natural antioxidants from tomato extract reduce blood pressure in patients with grade-1 hypertension: a double-blind, placebo-controlled pilot study. Am Heart J 151: 100, 2006.

11. Block G, Mangels AR, Norkus EP, et al: Ascorbic acid status and subsequent diastolic and systolic blood pressure. Hypertension 37: 261-267, 2001.

12. Ward NC, Wu JH, Clarke MW, et al: The effect of vitamin E on blood pressure in individuals with type 2 diabetes: a randomized, double-blind, placebo-controlled trial. J Hypertens 25: 227-234, 2007.

13. Taniguchi N: Superoxide dismutases: significances in aging, diabetes, ischemia and cancer. Rinsho Byori 38: 876-881, 1990 (In Japanese).

14. Autor AP, Frank L and Roberts RJ: Developmental characteristics of pulmonary superoxide dismutase: relationship to idiopathic respiratory distress syndrome. Pediatr Res 10: 154-158, 1976.

15. Skrzycki M, Majewska M, Podsiad M and Czeczot H: Expression and activity of superoxide dismutase isoenzymes in colorectal cancer. Acta Biochim Pol 56: 663-670, 2009.

16. Adler $\mathrm{S}$ and Huang $\mathrm{H}$ : Oxidant stress in kidneys of spontaneously hypertensive rats involves both oxidase overexpression and loss of extracellular superoxide dismutase. Am J Physiol Renal Physiol 287: F907-F913, 2004.

17. Chu Y, Iida S, Lund DD, et al: Gene transfer of extracellular superoxide dismutase reduces arterial pressure in spontaneously hypertensive rats: role of heparin-binding domain. Circ Res 92: 461-468, 2003.

18. Zhou L, Xiang W, Potts J, et al: Reduction in extracellular superoxide dismutase activity in African-American patients with hypertension. Free Radic Biol Med 41: 1384-1391, 2006.

19. Kumar CA and Das UN: Lipid peroxides, anti-oxidants and nitric oxide in patients with pre-eclampsia and essential hypertension. Med Sci Monit 6: 901-907, 2000.

20. Djordjević VB, Pavlović D, Pejović M, et al: Changes of lipid peroxides and antioxidative factors levels in blood of patients treated with ACE inhibitors. Clin Nephrol 47: 243-247, 1997.

21. Koska J, Syrova D, Blazicek, et al: Malondialdehyde, lipofuscin and activity of antioxidant enzymes during physical exercise in patients with essential hypertension. J Hypertens 17: 529-535, 1999.

22. Yamada H, Yamada Y, Adachi T, et al: Polymorphism of extracellular superoxide dismutase (EC-SOD) gene: relation to the mutation responsible for high EC-SOD level in serum. Jpn J Hum Genet 42: 353-356, 1997.

23. Campo S, Sardo AM, Campo GM, et al: Extracellular superoxide dismutase (EC-SOD) gene mutations screening in a sample of Mediterranean population. Mutat Res 578: 143-148, 2005

24. Sandström J, Nilsson P, Karlsson K and Marklund SL: 10-fold increase in human plasma extracellular superoxide dismutase content caused by a mutation in heparin-binding domain. J Biol Chem 269: 19163-19166, 1994.

25. Marklund SL, Nilsson P, Israelsson K, et al: Two variants of extracellular-superoxide dismutase: relationship to cardiovascular risk factors in an unselected middle-aged population. J Intern Med 242: 5-14, 1997.

26. Adachi T and Wang XL: Association of extracellular-superoxide dismutase phenotype with the endothelial constitutive nitric oxide synthase polymorphism. FEBS Lett 433: 166-168, 1998.

27. Yamada H, Yamada Y, Adachi T, et al: Molecular analysis of extracellular-superoxide dismutase gene associated with high level in serum. Jpn J Hum Genet 40: 177-184, 1995.

28. Iida R, Tsubota E, Takeshita $\mathrm{H}$ and Yasuda T: Multiplex single base extension method for simultaneous genotyping of non-synonymous SNP in the three human SOD genes. Electrophoresis 29: 4788-4794, 2008.

29. Ferroni P, Basili S, Paoletti V and Davì G: Endothelial dysfunction and oxidative stress in arterial hypertension. Nutr Metab Cardiovasc Dis 16: 222-233, 2006.

30. Node K, Kitakaze M, Yoshikawa H, Kosaka H and Hori M: Reduced plasma concentrations of nitrogen oxide in individuals with essential hypertension. Hypertension 30: 405-408, 1997. 
31. Sandrim VC, de Syllos RW, Lisboa HR, Tres GS and Tanus-Santos JE: Influence of eNOS haplotypes on the plasma nitric oxide products concentrations in hypertensive and type 2 diabetes mellitus patients. Nitric Oxide 16: 348-355, 2007.

32. Raman CS, Li H, Martásek P, et al: Crystal structure of constitutive endothelial nitric oxide synthase: a paradigm for pterin function involving a novel metal center. Cell 95: 939-950, 1998.

33. Moon J, Yoon S, Kim E, et al: Lack of evidence for contribution of Glu298Asp (G894T) polymorphism of endothelial nitric oxide synthase gene to plasma nitric oxide levels. Thromb Res 107 129-134, 2002.

34. Metzger IF, Souza-Costa DC, Marroni AS, et al: Endothelial nitric oxide synthase gene haplotypes associated with circulating concentrations of nitric oxide products in healthy men. Pharmacogenet Genomics 15: 565-570, 2005.

35. Li R, Lyn D, Lapu-Bula R, et al: Relation of endothelial nitric oxide synthase gene to plasma nitric oxide level, endothelial function, and blood pressure in African Americans. Am J Hypertens 17: 560-567, 2004.

36. Yoon Y, Song J, Hong SH and Kim JQ: Plasma nitric oxide concentrations and nitric oxide synthase gene polymorphisms in coronary artery disease. Clin Chem 46: 1626-1630, 2000.

37. Song J, Yoon Y, Park KU, et al: Genotype-specific influence on nitric oxide synthase gene expression, protein concentrations, and enzyme activity in cultured human endothelial cells. Clin Chem 49: 847-852, 2003.

38. Metzger IF, Sertório JT and Tanus-Santos JE: Modulation of nitric oxide formation by endothelial nitric oxide synthase gene haplotypes. Free Radic Biol Med 43: 987-992, 2007.

39. Tamai M, Furuta H, Kawashima H, et al: Extracellular superoxide dismutase gene polymorphism is associated with insulin resistance and the susceptibility to type 2 diabetes. Diabetes Res Clin Pract 71: 140-145, 2006.
40. Samoila OC, Carter AM, Futers ST, et al: Polymorphic variants of extracellular superoxide dismutase gene in a Romanian population with atheroma. Biochem Genet 46: 634-643, 2008.

41. Mansego ML, Solar Gde M, Alonso MP, et al: Polymorphisms of antioxidant enzymes, blood pressure and risk of hypertension. J Hypertens 29: 492-500, 2011.

42. Naganuma T, Nakayama T, Sato N, et al: A haplotype-based case-control study examining human extracellular superoxide dismutase gene and essential hypertension. Hypertens Res 31: 1533-1540, 2008.

43. Miyamoto Y, Saito Y, Kajiyama N, et al: Endothelial nitric oxide synthase gene is positively associated with essential hypertension. Hypertension 32: 3-8, 1998

44. Lacolley P, Gautier S, Poirier O, et al: Nitric oxide synthase gene polymorphisms, blood pressure and aortic stiffness in normotensive and hypertensive subjects. J Hypertens 16: 31-35, 1998.

45. Kato N, Sugiyama T, Morita H, et al: Lack of evidence for association between the endothelial nitric oxide synthase gene and hypertension. Hypertension 33: 933-936, 1999.

46. Benjafield AV and Morris BJ: Association analyses of endothelial nitric oxide synthase gene polymorphisms in essential hypertension. Am J Hypertens 13: 994-998, 2000.

47. Kingah PL, Luu HN, Volcik KA, et al: Association of NOS3 Glu298Asp SNP with hypertension and possible effect modification of dietary fat intake in the ARIC study. Hypertens Res 33: 165-169, 2010.

48. Zhao Q, Su SY, Chen SF, Li B and Gu DF: Association study of the endothelial nitric oxide synthase gene polymorphisms with essential hypertension in northern Han Chinese. Chin Med J (Engl) 119: 1065-1071, 2006 